\title{
A "Sorodiscordância" para Profissionais de Saúde: Estudo Qualitativo da Assistência em Ambulatório de HIVI AIDS em Município do Estado do Rio de Janeiro
}

\author{
Edith Lucia Mendes Lago \\ Instituto de Saúde da Comunidade da Universidade Federal Fluminense, Rio de Janeiro, Brasil \\ Programa de Pós-Graduação em Serviço Social da Pontifícia Universidade Católica \\ do Rio de Janeiro, Rio de Janeiro, Brasil \\ Ivia Maksud ${ }^{1}$ \\ Instituto de Saúde da Comunidade, Departamento de Planejamento em Saúde e Programa de \\ Pós-Graduação em Saúde Coletiva da Universidade Federal Fluminense, Rio de Janeiro, Brasil \\ Rafael Soares Gonçalves \\ Departamento de Serviço Social da Pontifícia Universidade Católica do Rio de Janeiro, \\ Rio de Janeiro, Brasil
}

\section{Resumo}

Este estudo examinou representações sociais de profissionais de saúde sobre a questão da sorodiscordância para o HIV/AIDS. A pesquisa foi realizada com profissionais inseridos em uma equipe multidisciplinar de um ambulatório especializado em HIV/AIDS no município de Niterói, no estado do Rio de Janeiro. Para tanto, foram realizadas com esses profissionais entrevistas semiestruturadas com o objetivo de compreender como as relações institucionais influenciam a visão da sorodiscordância e as representações que os profissionais têm acerca desse fenômeno. O texto pretendeu colocar em debate entendimentos dos entrevistados sobre os seus cotidianos profissionais, repercussões acerca das recentes recomendações e diretrizes do Ministério da Saúde no que concerne às políticas públicas de saúde e suas relações com a sorodiscordância, bem como documentos não oficiais (produzidos no âmbito de organizações não governamentais ligadas à área do HIV/AIDS). Este estudo evidencia e analisa as principais dificuldades encontradas pela equipe para a absorção dessa nova rotina de trabalho, e, brevemente, apresenta como fatores interferentes aspectos ligados à cultura institucional e à educação permanente dos profissionais da saúde dentro do ambiente institucional. A pesquisa pretende contribuir para a adequação de rotinas que contemplem, da melhor forma, o fenômeno da sorodiscordância, possibilitando uma assistência mais adequada às dinâmicas sociais vivenciadas pelos usuários.

Palavras-chave: AIDS, sorodiscordância, equipe profissional.

\section{The "Serodiscordance" for Health Professionals: A Qualitative Study of Ambulatory Care of HIVIAIDS in the Municipality of the State of Rio de Janeiro}

\begin{abstract}
This article examines the social representations that a multidisciplinary team of professionals which works in an ambulatory specialized in HIV / AIDS have on the issue of the serodiscordance. The resear-
\end{abstract}

Endereço para correspondência: Instituto de Saúde da Comunidade, Departamento de Planejamento em Saúde, Av. Marquês de Paraná, 303, $4^{\circ}$ andar (Predio anexo ao HUAP), Centro, Niterói, RJ, Brasil. CEP 24030-210. E-mail: edithmendeslago@gmail.com, iviamaksud@id.uff.br e rafaelsgoncalves@yahoo.com.br 
ch presents the new recommendations from the Ministry of Health for the matters that involve serodiscordance and analyzes its answers in the daily services. The interviews with professionals in the clinic were semi-structured, combining three elements: social-demographic data, in order to learn issues that affect the interviewed people social status, institution data, to understand how relationships influence the institutional vision of the serodiscordance, and data on serodiscordance whose objective is to understand the professional representations on the subject. The study highlights and analyzes the main difficulties found by the team for taking up this new routine of work and presents interfering factors aspects of institutional culture and permanent education. This article contributes to the possibility of change and adaptation of routines that look at the phenomenon of serodiscordance better.

Keywords: AIDS, serodiscordance, multidisciplinary team.

\section{La "Serodiscordancia" para Profesionales de la Salud: Un Estudio Cualitativo de la Atención Ambulatoria del VIH/SIDA en el Municipio del Estado de Río de Janeiro}

\section{Resumen}

Esto estudio examinó las representaciones sociales de los profesionales de la salud sobre la cuestión de la serodiscordancia para el VIH / SIDA. La investigación se realizó con entrevistas con profesionales de un equipo multidisciplinario de un servicio especializado en VIH / SIDA en el Hospital de la ciudad de Niterói, estado de Río de Janeiro. Por lo tanto, fueron realizadas 11 entrevistas semi-estructuradas a partir de tres ejes: datos sociodemográficos, con el fin de comprender las cuestiones de pertenencia social de los entrevistados; información sobre la institución, con el fin de entender cómo las relaciones institucionales influyen en la visión de la serodiscordancia; los datos sobre la serodiscordancia, con el objetivo de aprovechar las representaciones que los profesionales tienen sobre esto fenómeno. De la relación de estos datos, la presente investigación buscó examinar la comprensión de los entrevistados acerca de su día a día profesional y las repercusiones sobre las recientes recomendaciones y directrices del Ministerio de Salud con respecto a las políticas de salud pública y sus relaciones con la serodiscordancia. Esto estudio destaca y analiza las principales dificultades encontradas por el equipo para absorber esto nuevo trabajo de rutina, y brevemente se presenta como una interferencia en los aspectos de factores de la cultura institucional y la educación continuada de los profesionales de la salud en el entorno institucional. La investigación pretende contribuir a las rutinas de acondicionamiento físico que incluyen de la mejor manera el fenómeno de la serodiscordancia, para que se permita una asistencia más adecuada a la dinámica social experimentada por los usuarios.

Palabras clave: SIDA, serodiscordancia, el personal profesional.

A AIDS tornou-se a pandemia mais desafiadora dos últimos anos. Até o momento de realização desta pesquisa, as tendências quanto à infecção no contexto brasileiro se orientavam para o que vinha sendo chamado, sobretudo pelo discurso oficial, de "feminização", "juvenização" e "pauperização" da doença. Tais tendências, se analisadas criticamente, conforme fizeram Parker e Camargo Jr. (2000), chamam a atenção para um contexto de configuração de várias epidemias de HIV/AIDS que ocorrem paralelamente no país, as quais são determinadas por sua dimensão continental e por suas variações socioeconômicas e demográficas, "configurando, portanto, diferentes vulnerabilidades à infecção pelo HIV e, por conseguinte, à AIDS" (Parker \& Camargo Jr., 2000, p. 90).

No início da epidemia, a sentença de morte que pairava sobre as cabeças de todas as pessoas que se infectaram com o vírus HIV provocava grande incerteza, tanto nos pacientes quanto nos profissionais de saúde que lhes prestavam assistência médica, pois pouco se sabia sobre a doença e sobre as chances de sobrevida que os 
pacientes poderiam ter. Por muito tempo, foi utilizado nos serviços de saúde o termo "paciente terminal" para nomear aqueles que já estavam em franco processo de adoecimento. Ao longo desse período foram registrados muitos avanços no tratamento da AIDS, os quais vão desde a alteração do próprio esquema da medicação, passando pelas rotinas de tratamento cada vez mais abrangentes e interdisciplinares, até os avanços do campo social, constantemente impulsionados pela força do movimento da sociedade civil organizada. O Brasil, sobretudo nos anos 90 e 2000, destacou-se no cenário mundial pela eficácia de sua política, implementada - após grande mobilização envolvendo ativistas, profissionais de saúde e pesquisadores - através da rede do Sistema Único de Saúde (SUS), onde o tratamento com os ARVs - medicação antirretroviral - é disponibilizado aos pacientes universalmente, incluindo os exames laboratoriais e as medicações para o combate das doenças oportunistas.

Em relação à temática da sorodiscordância, o mesmo aconteceu. Caracterizada por uniões conjugais em que um dos parceiros está infectado pelo HIV e o outro, não, esta modalidade de relacionamento passa a ser cada vez mais freqüente (R. R. Remien, 2002; R. H. Remien, Carballo-Dieguez, \& Wagner, 1995), em parte pela melhoria da qualidade e expectativa de vida das pessoas soropositivas. No caso do Brasil, estes fatos podem ser, talvez, relacionados ao acesso a uma "rede estruturada para o atendimento integral às pessoas vivendo com HIV", incluindo aconselhamento, testagem, medicamentos antirretrovirais, acesso a exames, para garantir "tratamento e cuidados, prolongamento da sobrevida e melhoria da qualidade e vida às pessoas soropositivas" (Hallal, Ravasi, Kuchenbecker, Greco, \& Simão, 2010).

Por envolver várias questões relacionais de várias ordens, seja a relação entre os parceiros, seja a relação destes com profissionais de saúde, serviços ou com outras redes sociais, a "sorodiscordância" se configura como objeto sociológico que permite observar como determinadas regras sociais em relação à doença se colocam diante da esfera afetivo-sexual dos sujeitos (Maksud, 2007, 2012).
Este artigo deriva de pesquisa que teve como objetivo analisar as representações sociais que a equipe de saúde de um ambulatório especializado de HIV/AIDS tem acerca do fenômeno da sorodiscordância, bem como evidenciar as principais dificuldades da equipe para o desenvolvimento de trabalhos que incluam tal questão, integralizando ações no campo da assistência e no campo da prevenção (Lago, 2011).

Neste texto, após contextualização do universo no qual estão inseridos os profissionais de saúde entrevistados, passaremos à apresentação breve das principais questões contidas nas recomendações das políticas de saúde atuais relacionadas à temática da sorodiscordância para então discutir as representações sociais e os conhecimentos, em termos de prevenção e assistência, dos profissionais de saúde acerca das práticas sexuais e dos desejos reprodutivos de casais sorodiscordantes. De forma complementar, breves apontamentos são feitos a partir das lacunas encontradas na formação continuada dos profissionais de saúde que expressam tais representações.

As representações sociais vêm sendo estudadas por diversos autores ao longo dos anos. O termo representação coletiva foi proposto primeiramente por Durkheim, que desejava destacar a primazia do pensamento social em detrimento do pensamento individual. Herzlich (2005, p. 58) assinala que, para Durkheim, a representação coletiva seria muito mais que a simples soma das representações individuais, possuindo, neste caso, uma existência própria, não passível de mudança pela ação do indivíduo. Segundo a autora, em 1961, ao analisar as representações sociais da psicanálise, Moscovici retrabalha a noção do social proposta por Durkheim, atribuindo-lhe um sentido mais pleno que levaria em consideração o sujeito como construtor de seu próprio mundo a partir do que a sociedade lhe fornece. Os sociólogos - esclarece Herzlich - dentre eles Bourdieu, Passeron e Chamboredon, também empreenderam suas críticas a Moscovici, sendo a principal delas a impossibilidade de explicar "o funcionamento de um sistema com base no sentido que a apreensão imediata dos atores individuais lhes atribui de forma espontânea" (Herzlich, 2005, p. 62). 
Autoras como Spink (2004) concebem as representações sociais como estruturas que encontram aporte no social, mas que também são expressões da realidade intraindividual:

Nesta vertente a elaboração das representações sociais, enquanto formas de conhecimento prático que orientam as ações do cotidiano, se dá na interface de duas forças monumentais. De um lado temos os conteúdos que circulam em nossa sociedade e, de outro, temos as forças decorrentes do próprio processo de interação social e as pressões para definir uma dada situação de forma a confirmar e manter identidades coletivas. O contexto, neste sentido, é essencialmente "intertextual”, ou seja, é a justaposição dos dois textos: o texto sócio-histórico que remete às construções sociais que alimentam nossa subjetividade; e o texto-discurso, versões funcionais constituintes de nossas relações sociais. (Spink, 2004, p. 122)

Nesta perspectiva, as representações sociais contribuem para entender não só as "marcas sociais do cognitivo" (Spink, 2004), mas também os processos sociais que possibilitaram essas expressões.

Pela natureza dessas questões, intencionamos colocar, implicitamente, em diálogo, as representações sociais sobre "a sorodiscordância" com alguns dos "sentidos da integralidade", tais como discutidos por Mattos $(2004,2009)$, resultando daí um olhar para o fenômeno a partir da integração entre os diversos níveis de complexidade da ação em saúde; o encontro com o outro, com poder se colocar em seu lugar e compreendê-lo para estabelecer um plano terapêutico individualizado e de maior eficácia; e, por fim, vislumbrar possibilidades de reorientação dos serviços a partir da compreensão da centralidade do usuário.

\section{Metodologia}

$\mathrm{O}$ artigo baseia-se em dados de pesquisa realizada em duas etapas. A primeira delas consistiu em levantamento bibliográfico e documental sobre o tema em questão. Para este texto destacamos documentos oficiais e não oficiais que se ocuparam da discussão acerca de recomen- dações para prevenção e tratamento no contexto da soropositividade, em que a sorodiscordância também se colocava como horizonte de discussão. A segunda etapa da pesquisa consistiu na realização de entrevistas com profissionais de saúde que trabalham em um ambulatório especializado na atenção de pessoas soropositivas em um município do Estado do Rio de Janeiro. Neste cenário foram realizadas entrevistas semi-estruturadas com os profissionais que compunham a equipe multidisciplinar do referido ambulatório. Ao fim das entrevistas, a pesquisadora que conduziu as entrevistas solicitava ao entrevistado que não revelasse os assuntos contidos na entrevista aos demais profissionais de saúde. Explicava aos entrevistados que, como aquele era um grupo muito pequeno, quaisquer comentários poderiam influenciar as demais entrevistas. Em muitas ocasiões, a entrevistadora observou que o profissional de saúde estava refletindo pela primeira vez sobre os assuntos abordados no momento da entrevista e, justamente por não ter ideia pré-concebida sobre o que estava sendo perguntado, divagava sobre o tema como se estivesse conversando com ele mesmo.

$O$ roteiro das entrevistas articulava três eixos: (a) dados sóciodemográficos, com o objetivo de apreender questões afetas ao pertencimento social dos entrevistados; (b) dados sobre a instituição, que visava compreender se as relações institucionais influenciam na abordagem do fenômeno em questão; (c) dados sobre a sorodiscordância para o HIV/AIDS, que registraram e, posteriormente, permitiram analisar as representações sociais que os profissionais de saúde têm sobre o fato. Além desse instrumento, foi utilizado também um diário de campo em que foram registradas impressões pessoais acerca da entrevista, curiosidades ou reflexões acerca de fatos que chamassem a atenção durante o processo. Situações singulares, como emoções em determinados trechos da entrevista, pausas e revelações sigilosas, também foram registradas e constituíram elementos que embasaram a análise.

A realização das entrevistas ocorreu nos meses de outubro e novembro de 2010. As entrevistas foram restritas à equipe de "técnicos" especialistas do ambulatório. Foram excluídos 
os "técnicos" administrativos e os auxiliares de enfermagem e, à exceção de uma, todas as entrevistas foram realizadas no ambulatório de especialidades em uma das salas de consulta. A única entrevista realizada fora da instituição ocorreu em um posto de saúde da rede de Niterói.

Geralmente, as entrevistas eram marcadas previamente por telefone e agendadas para o período da tarde. Elas foram realizadas, na maioria das vezes, ao final do atendimento aos pacientes. Tiveram, em média, uma hora e meia de duração.

$\mathrm{O}$ material coletado foi analisado à luz da teoria das representações sociais, buscando não só compreender as "marcas sociais do cognitivo" (Spink, 2004), mas também as condições cognitivas de seu processamento ideológico, conferindo-lhe, neste caso, a característica de processo social.

Seguimos os cuidados que Spink (2004) sugere para efetivação da análise das entrevistas: transcrição das fitas e leitura flutuante do material, intercalando a escuta das entrevistas grava- das com a leitura do texto transcrito, com objetivo de perceber a retórica, os detalhes sutis, as versões contraditórias, os silêncios, bem como definir os pontos relevantes do discurso para posterior discussão. Cabe ressaltar que a todo o momento foi mantida a preocupação de articular a análise das categorias que surgiram no estudo - que envolvia representações sociais do grupo pesquisado - ao contexto mais geral, ou seja, às inovações que estão acontecendo recentemente.

A pesquisa foi aprovada pelo Comitê de Ética em Pesquisa da Universidade Federal Fluminense, segundo a resolução ${ }^{\circ} 196 / 96$ do Conselho Nacional de Saúde (CNS, 2007). Todos os entrevistados concordaram em dela participar, tendo assinado o termo de consentimento livre e esclarecido, e declarando estar de acordo com seus objetivos.

\section{Resultados}

\section{Perfil e Localização dos Entrevistados}

Tabela 1

Quadro Sinóptico dos Entrevistados

\begin{tabular}{|c|c|c|c|c|c|c|c|c|c|c|c|c|c|c|}
\hline $\mathrm{T}^{0}$ & $S^{1}$ & $1^{2}$ & Religião & $\begin{array}{c}\text { Ano de } \\
\text { graduação }\end{array}$ & $\begin{array}{l}\text { Instituição } \\
\text { de } \\
\text { graduação }\end{array}$ & \multicolumn{2}{|c|}{ Residência } & \multicolumn{2}{|c|}{ Especialização } & \multicolumn{2}{|c|}{ Mestrado } & \multicolumn{2}{|c|}{ Doutorado } & $\begin{array}{c}\text { Tempo de trabalho } \\
\text { com a AIDS } \\
\text { (anos) }\end{array}$ \\
\hline T 1 & $\mathrm{~F}$ & 56 & Católica & 1978 & UFF & Não & - & Sim & 1 & Sim & 1 & Não & - & 13 anos \\
\hline Т 2 & $\mathrm{~F}$ & 43 & Espírita & 1991 & PUC & Não & - & Sim & 1 & Não & - & Não & - & 10 anos \\
\hline T 3 & $\mathrm{~F}$ & 58 & Católica & 1979 & UFF & Não & - & Não & - & Não & - & Não & - & 8 anos \\
\hline T 4 & $\mathrm{~F}$ & 47 & Espírita & 1987 & UFF & Não & - & Sim & 2 & Não & - & Não & - & 20 anos \\
\hline T 5 & $M$ & 44 & Agnóstico & 1990 & UFRJ & Sim & 1 & Sim & 1 & Não & - & Não & - & 26 anos $^{3}$ \\
\hline T 6 & $\mathrm{~F}$ & 51 & Católica & 1984 & FMT & Não & - & Sim & 1 & Não & - & Não & - & 23 anos \\
\hline T 7 & $\mathrm{~F}$ & 49 & Católica & 1983 & UFRJ & Não & - & Sim & 1 & Não & - & Não & - & 26 anos \\
\hline T 8 & $\mathrm{~F}$ & 35 & Espírita & 1999 & FMT & Sim & 1 & Sim & 1 & Não & - & Não & - & 10 anos \\
\hline Т 9 & $M$ & 60 & Agnóstico & 1977 & EMCRJ & Não & - & Sim & 2 & Não & - & Não & - & 30 anos \\
\hline Т 10 & $\mathrm{~F}$ & 38 & Católica & 1995 & UFF & Sim & 1 & Sim & 1 & Não & - & Não & - & 1 mês e meio \\
\hline Т 11 & $\mathrm{~F}$ & 45 & Católica & 1987 & UFF & Não & - & Sim & 2 & Não & - & Não & - & 19 anos \\
\hline
\end{tabular}

Notas. ${ }^{0}$ Técnico; ${ }^{1}$ Sexo; ${ }^{2}$ Idade. Fonte: Lago, 2011. Legendas: UFF $=$ Universidade Federal Fluminense; PUC $=$ Pontifícia Universidade Católica; UFRJ= Universidade Federal do Rio de Janeiro; FMT= Faculdade de Medicina de Teresópolis; EMCRJ= Escola de Medicina e Cirurgia do Rio de Janeiro.

Os entrevistados serão referidos, ao longo do texto, como "técnicos". Eles compõem uma equipe formada por cinco médicos, uma assistente social, três enfermeiras, uma psicóloga e uma nutricionista. A não identificação das profissões dos entrevistados no quadro resulta de decisão tomada na pesquisa original: visava resguardar a identidade dos entrevistados, que poderiam reconhecer-se ao ler análises realizadas a partir dos dados coletados (Lago, 2011).

Conforme pode ser visto no quadro acima, a maioria dos membros da equipe é formada por 
mulheres. Dos onze entrevistados, só há dois homens e ambos de profissão médica. Dos onze integrantes da equipe, seis se declararam católicos, três espíritas e dois agnósticos. A idade dos componentes da equipe varia muito, mas fica compreendida no intervalo de 35 a 60 anos. A maioria foi formada em universidades públicas, e apenas um "técnico" não tem pós-graduação. Dos onze entrevistados, seis deles têm, em média, duas pós-graduações e um tem mestrado.

Os "técnicos" possuem vinculação pública, excetuando-se os médicos. Destes últimos, apenas um tem vínculo público; os outros quatro são contratados por meio de chamados "contratos temporários". Contudo, o salário e a carga horária são iguais para os dois tipos de vínculo. Além disso, esses contratados não são muito recentes; alguns deles têm mais de dez anos de atuação dentro do ambulatório. A explicação dada por eles para o fenômeno da contratação é a falta de especialistas que lidem com a questão do HIV/ AIDS na rede de serviços. Estes conformam um grupo muito pequeno, em que todos se conhecem. Por esse motivo, quando há falta de profissionais para um cargo vago, os próprios médicos da equipe ficam incumbidos de indicar algum outro profissional para a coordenação do setor, e esta para indicá-los à direção do hospital.

\section{Breve Análise do Plano das Políticas: O que Dizem Recentes Documentos}

O status de doença crônica da AIDS tem apresentado às equipes de saúde novos desafios, tais como o estímulo ao paciente a um tratamento contínuo e o respeito aos direitos sexuais e reprodutivos.

Dentre os desafios colocados aos serviços e profissionais de saúde figuram a manutenção (ou busca) de uma boa qualidade de vida para o parceiro soropositivo, a prevenção do parceiro soronegativo, a revelação do diagnóstico ao parceiro e a familiares e a aceitação da doença pelo próprio paciente mediante uma sociedade que ainda percebe a AIDS como uma doença "do outro".

$\mathrm{O}$ atendimento contínuo aos pacientes soropositivos que se encontram em relacionamentos estáveis e de longa duração com pessoas soronegativas compreende ainda outros desafios para a saúde pública, por um lado, e para os sujeitos, por outro, tais como a manutenção da utilização do preservativo, a possibilidade de soroconversão do parceiro e os desejos reprodutivos, assuntos que por sua complexidade ampliam a concepção tradicional do que seja o tratamento e colocam em evidência normas, crenças, desejos e valores, tanto de pacientes quanto de profissionais de saúde.

A temática da "sorodiscordância"- enquanto fato perceptível e reconhecível - é relativamente nova no cenário dos ambulatórios brasileiros. Sua ampla discussão pode contribuir para a reorientação de condutas e ações dos profissionais nos serviços de saúde. Mas, se no cenário dos serviços de saúde o tema ainda carece de visibilidade, o mesmo tem sido acompanhado pelos movimentos sociais, academia e pelos formuladores de políticas públicas nos últimos anos.

$\mathrm{Na}$ última década, recomendações e diretrizes de políticas públicas de saúde estão sendo paulatinamente introduzidas pelo Ministério da Saúde na rede de serviços, de modo geral. Algumas delas são especialmente importantes e estabelecem interface com a atenção especializada na área do HIV/AIDS. Podemos citar como exemplos a rotina preconizada para mulheres em situação de violência, o programa de redução de danos, e as diretrizes para um atendimento humanizado e integral.

Neste artigo vamos nos deter em alguns documentos que consideramos oportuno trazer para o debate da sorodiscordância. Eles se referem ao marco da estratégia de "prevenção posithiva" que, de certa forma, contribuiu para o debate das políticas de saúde, e às recomendações de tratamento para o HIV/AIDS a serem seguidas pelos profissionais de saúde em todo o país.

No ano 2002, a organização não-governamental ABIA (Associação Brasileira Interdisciplinar de AIDS) promoveu um seminário intitulado "Conjugalidade e AIDS: A Sorodiscordância e os Serviços de Saúde", com o objetivo de abrir as discussões sobre essa temática. Cinco anos mais tarde (2007), a ABIA promoveu segundo encontro para discutir questões relativas ao cuidado e a prevenção da AIDS, discussão que fora nomeada de "prevenção posithiva" a partir de então. A partir de encontros como esses, em que se reuniram ativistas, academia e governos, 
ficou flagrante a necessidade de se reformular, no âmbito das políticas de saúde voltadas para o HIV/AIDS, algumas linhas diretivas de ação a partir da contribuição das várias áreas de conhecimento envolvidas com a questão da epidemia.

Segundo o documento elaborado pela ABIA a partir de oficina que reuniu diferentes atores presentes no seminário, a "Prevenção Posithiva" não poderia ser considerada efetivamente uma política pública mas uma estratégia, uma vez que as discussões em torno do assunto ainda precisavam amadurecer (Raxach, Maksud, Pimenta, \& Terto, 2009). Contudo, já existe um consenso entre os profissionais que lidam com essa questão de que já é possível auferir linhas mais gerais, como uma espécie de protocolo de intenções. Uma das compreensões mais relevantes nesse processo é a de que o foco de atuação da prevenção deve ser desvencilhado do modelo biomédico que culpabiliza o paciente e reduz a prevenção à utilização do preservativo.

A esse respeito, no mesmo documento, Barcellos (2009) ressaltou que aquilo que se deseja imprimir é uma nova noção de prevenção que descarta a ideia de que ela seja somente para evitar a transmissão do HIV a outras pessoas. Essa nova perspectiva de prevenção engendra a noção do cuidado e da integralidade da saúde, introduzindo também a questão da subjetividade como algo a ser valorizado pelos profissionais no dia a dia dos serviços, já que a história de vida do paciente, seus sentimentos, seus desejos e suas representações interferem de maneira decisiva no processo saúde-doença.

A amplitude desta linha de atuação envolve a garantia do acesso à medicação, a atenção psicossocial, o desenvolvimento de novas estratégias para uma melhor adesão ao tratamento preconizado, o desenvolvimento de novas propostas clínicas mais condizentes com as novas descoberta em relação à epidemia, bem como o direito a uma vida sexual saudável, ativa e, neste caso, que compreenda o direito à reprodução. Nesse sentido, pode-se discutir, por exemplo, que tipos de estratégias estão ao alcance da equipe técnica para que se possa diminuir o risco de infecção entre casais sorodiscordantes; ou que novos olhares a equipe deve imprimir para trabalhar melhor com estas realidades?
As Recomendações para a Terapia Antirretroviral em Adultos Infectados pelo HIV (documento conhecido por profissionais de saúde como "Consenso") constituem uma publicação bianual elaborada por um comitê assessor composto de especialistas reunidos pelo Ministério da Saúde (MS) que avaliam e regulamentam a inclusão de novos medicamentos para o tratamento da doença, a serem utilizados em todo país. Além disso, essa publicação define outras recomendações específicas para a assistência às pessoas que vivem com HIV/AIDS. Para este artigo é importante sinalizar que a edição até então mais recente desse documento (datada de 2010) apresenta um suplemento com algumas inovações que incidem claramente na questão da sorodiscordância.

A primeira inovação a ser considerada está relacionada à questão da reprodução no contexto da sorodiscordância. Já a segunda é a inclusão de indicação de profilaxia pós-exposição sexual para parceiros sorodiscordantes nos serviços, incluindo exposições a relações sexuais eventuais. O novo "Consenso" tem como pressuposto que "o planejamento familiar é um direito sexual e reprodutivo" (MS, 2010), e, por isso, estabelece novas regras para minimizar os riscos da transmissão do HIV pelo ato sexual, prevê uma rotina clara para os casos de exposição pós-sexual, bem como propõe que todas as questões que envolvem a reprodução sejam amplamente discutidas e integralizadas ao ambiente dos serviços. O rebatimento dessa inovação nos serviços é, de fato, de grande importância, pois é aí que talvez se encontrem soluções para os "acidentes de percurso" que tanto afligem a equipe do ambulatório de especialidades que lida com a rotina pós-exposição sexual de casais sorodiscordantes.

Como não havia uma rotina clara para isso (a primeira recomendação só foi feita no "Consenso" de 2006 sem grande repercussão nos serviços), muitas vezes o parceiro soronegativo, após ter rompido o preservativo durante o ato sexual, procurava o serviço de referência, mas não tinha uma solução para o seu problema. Alguns dados da pesquisa sugerem que embora alguns desses serviços deixassem o paciente à sua própria sorte, sem a oferta da medicação adequada, as medidas eram, então, tomadas caso a caso, de 
acordo com as práticas do próprio serviço, que, ou burlava as regras e fazia a rotina da profilaxia por sua própria conta, ou não dispensava os medicamentos deixando as pessoas sem assistência.

Entender como tais questões vêm repercutindo entre os profissionais nos serviços é especialmente relevante, já que tal dinâmica envolve a resposta dos serviços à rotina dos pacientes atendidos e influi diretamente em seus planos terapêuticos.

\section{A Assistência a Casais Sorodiscordantes: Representações Sociais em Construção}

A pesquisa revelou que, de forma prevalente, as relações sorodiscordantes não são percebidas positivamente e/ou encorajadas pelos profissionais de saúde. No imaginário dos profissionais, tais relações são vistas como conflituosas e tensas, como se a divergência encontrada no status sorológico se estendesse ao plano afetivo, conforme se pode ver, por exemplo, abaixo:

Entrevistadora: $O$ que você acha dos relacionamentos entre pessoas com sorologias diferentes para o HIV/AIDS?

Entrevistado: Eu acho isso bastante complicado. Por que eu acho isso bastante complicado? A princípio, é uma relação bastante atritada. Por que bastante atritada? Porque o indivíduo, ao mesmo tempo em que ele tem que se cuidar, ele tem que se proteger para não estar soropositivo; ele passa naquela relação a estar sempre vinculado a um medo constante: e se a camisinha romper? E se... houver alguma coisa? . . (Técnico 9) Em nenhuma das entrevistas houve propriamente valoração da sorodiscordância enquanto relação afetivo-sexual. $\mathrm{O}$ fato de o parceiro negativo poder ser, por exemplo, um elo facilitador entre o paciente e o tratamento, não foi levado em conta por nenhum dos entrevistados, ainda que vários estudos (Knauth, 2002; Maksud, 2007, 2012; Polejack, 2001) apontem a presença de parceiros soronegativos exercendo atividades de cuidado com o seu companheiro/a, ou o fortalecimento do vínculo afetivo, da solidariedade, e da elaboração de projetos motivadores de vida em comum.
Apesar de todos os entrevistados afirmarem que a sorodiscordância não é um fato muito concreto dentro do ambulatório de especialidades, alguns contaram episódios sobre casais que se encontravam nessa modalidade de relação durante o próprio processo de entrevista ou depois de sua realização, revelando, na verdade, um paradoxo: as relações existem de fato, mas não são percebidas/legitimadas pelos profissionais de saúde enquanto tais. A representação negativa da sorodiscordância pelos "técnicos" do serviço certamente contribui para a ocorrência de um possível "apagamento simbólico" (Maksud, Terto, Pimenta, \& Parker 2002) sobre a existência de relacionamentos sorodiscordantes dentro do serviço, justificando uma demanda que existe concretamente, mas que não é percebida e por que não é percebida também não pode ser trabalhada, conforme pode ser visto na entrevista abaixo:

Entrevistadora: "Você atende ou já atendeu a casais sorodiscordantes aqui? Fale-me sobre sua experiência".

Entrevistado: "Diretamente não. Ele chega mais pra gente quando a discordância vira concordância, né? ..." (Técnico 5).

No discurso dos entrevistados, o não atendimento do serviço ao parceiro soronegativo justifica-se pelo fato deste não ser paciente formal do sistema, lógica contrária à prevenção e que parece obedecer a uma organização do serviço que desprestigia o indivíduo são e desconsidera que a AIDS é uma doença sexualmente transmissível que, por sua natureza, exige, pelo menos, o monitoramento dos parceiros (Ministério da Saúde, 2000).

Apenas dois "técnicos" foram categóricos em dizer que não abordam o parceiro porque eles não fazem parte da rotina do serviço; os demais informaram que até o abordam, mas que esta abordagem não tem o "caráter" de atendimento, que são conversas na sala de espera quando se esbarram pelos corredores, quando vão atender a uma determinada demanda solicitada pelo parceiro. Esses profissionais reconheceram que quase sempre fazem essa abordagem com uma única questão em mente: saber se o casal está usando preservativo nas relações sexuais. Essa "conversa informal" deve ser muito valorizada. 
Sabe-se que muitos problemas dos pacientes são expostos nessa hora, e que muitas vezes são estimulados por outros pacientes que passam ou já passaram por situações parecidas. De forma similar, as conversas de sala de espera são ricas para qualquer profissional atento, preocupado com a reorientação de ações que possam proporcionar a melhoria das intervenções no âmbito do serviço. No entanto, a preocupação em saber se os casais estão usando preservativo ou não deve ser relativizada para não se tornar "policiamento".

Já atendi casais homossexuais e casais heterossexuais. . . uma das pessoas que eu atendo, o parceiro não sabe que ele é portador do vírus HIV, o parceiro não sabe, é um relacionamento longo, eles convivem há mais de 10 anos e... não consegue, não quer, não consegue falar sobre isso, sobre esse assunto. Acha que o relacionamento pode acabar ou não tem, não se sente seguro, tem medo de ser abandonado, medo... Medo. Ele fica muito amedrontado; por outro lado também, se preocupa muito em como não contaminar o outro, como não contaminar o parceiro. (Técnico 2)

O entrevistado acima explicita a tensão que casais com sorologias distintas enfrentam quanto ao medo de revelar e a vontade de confessar. O discurso também aponta para outro fator; para o parceiro negativo também é difícil a administração da situação uma vez que a sua identificação com o parceiro lhe impulsiona para a possibilidade de "tornar-se igual", conforme a própria entrevistada complementa:

“. . . Quando é sabido que o casal é sorodiscordante, quer dizer, a outra parte sabe, muitas vezes, eu acho que é dificil para quem não é soropositivo suportar a diferença, ser diferente" (Técnico 2).

Em um dos dias em que as entrevistas foram realizadas, uma jovem chorava copiosamente durante uma consulta enquanto as técnicas de saúde tentavam acalmá-la. Como a entrevistadora não fazia parte da equipe, ela deixou o consultório e foi para a sala da administração a fim de permitir que as técnicas atuassem no caso com tranqüilidade. Posteriormente, durante o processo da entrevista, foi confirmado que se tratava de um caso de sorodiscordância, em que nem o parceiro da jovem e nem a família de ambos sabiam da soropositividade da mesma, que havia sido descoberta recentemente, na ocasião do seu parto, ao realizar a testagem rápida. $\mathrm{O}$ motivo de sua angústia, segundo as entrevistadas, foi a falta do antirretroviral que deve ser administrado ao bebê, de acordo com o protocolo específico que normatiza esses casos (Protocolo 076), pois ele havia caído no chão e quebrado. Além disso, a própria descoberta recente de sua soropositividade, naturalmente, contribuiu muito para o seu comportamento emocionado. Por fim, o remédio foi providenciado imediatamente pelas técnicas que estavam envolvidas no atendimento. Essas situações corriqueiras, acontecidas durante as entrevistas, mostram como os relacionamentos sorodiscordantes estão presentes no dia-a-dia do ambulatório de HIV/AIDS do serviço de saúde.

Outra dificuldade arrolada pelos profissionais está relacionada ao próprio atendimento do casal, conforme se encontra a seguir:

Entrevistadora: Que dificuldades você encontra para trabalhar com esse público? Entrevistado: Eu acho que a dificuldade maior é quando eles vêm os dois juntos à consulta. Por quê? Eles chegam à tua sala, em primeiro lugar, com aquele instinto de acusar: eu estou aqui por causa dela, eu estou aqui por causa dele. Então, a cobrança já entrou e já sentou. Então, você fica sempre vinculado à essa briga que eles trazem de casa para dentro da consulta. É por isso que eu não gosto de atender assim junto. Eu posso até atender o casal, não tem problema nenhum, mas eles vão ser atendidos separados. (Técnico 9)

Tradicionalmente o espaço da consulta é um espaço reservado. No entanto, considerando as novas propostas que estão sendo desenhadas para este público (MS, 2007), pode-se vislumbrar a possibilidade da construção de espaços específicos para o atendimento dos casais uma vez que eles têm dúvidas e questões específicas, que envolve a própria dinâmica dos relacionamentos. Fontenelle e Machado (2002) já relatam experiências com casais sorodiscordantes através de interconsultas e de grupos interativos para as discussões que envolvem a vida conjugal. São iniciativas isoladas, mas que poderiam 
oferecer uma base para a orientação de outros profissionais.

Outra dificuldade apontada foi a tendência para o segredo em várias situações que dizem respeito ao tratamento do soropositivo:

Entrevistadora: Que dificuldades você encontra para trabalhar com esse público? Entrevistado: Têm várias... A questão da medicação é uma dificuldade, porque precisa ter adesão ao tratamento. Então, fica, se o outro não sabe que ele é, então, tem que esconder que toma a medicação, esconder que faz tratamento, então, a vida vai ficando uma grande... tudo muito escondido, não é mentira, mas, fica uma vida dupla o tempo todo. Então, é muito dificil pro paciente manter esse segredo, guardar esse segredo... Ele sofre, ele sofre muito, e o parceiro também sofre, quando sabe, né? (Técnico 2) Para o entendimento da maioria dos especialistas, a rotina ambulatorial em nada facilita, mesmo que seja em pequena escala, a abordagem ao parceiro. Para outros, a rotina facilita essa abordagem. Entretanto, a despeito das opiniões pessoais, não há preparo por parte dos "técnicos" para melhor empreender essa abordagem:

Entrevistadora: Você acha que a rotina ambulatorial facilita a abordagem ao parceiro? Por quê?

Entrevistado: Facilita; só não acho que talvez estejamos preparados. Primeiro o médico tem uma papelada, ele visa mais o paciente em si e a coisa clínica; a psicóloga nem sempre os pacientes aceitam; é uma coisa muito... Não é uma presença dentro do ambulatório, não acho a psicologia presente neste ambulatório ou em nenhum outro. A psicologia está muito ausente; ela teria que estar mais presente nestes casos. Então, eu acho que os profissionais não estão preparados para isso. Ai a gente acaba vendo o colesterol alto, o clinico vê o CD4 baixo, a carga viral e a gente esquece de ver outras coisas que seriam importantes. (Técnico11) Outro aspecto importante que apareceu nas entrevistas foi a via de acesso a esses casais. Quando os "técnicos" aludiam a casos de sorodiscordância, eles se referiam sempre a casais cadastrados assistidos pelo ambulatório de HIV.
Entretanto, uma outra via de contato com esses pacientes está sendo subestimada: o aconselhamento, que absorve a demanda de fora e a demanda referenciada, como os pacientes internados e as gestantes do pré-natal. Estes, não necessariamente farão parte do serviço como usuários.

Durante o aconselhamento, quando se constata um caso de soropositividade, e depois das devidas orientações, os encaminhamentos para o tratamento obedecem à lógica de referenciação. Nesse caso, o paciente que faz o aconselhamento e se descobre positivo para o vírus é encaminhado para um serviço próximo de sua residência (Ministério da Saúde, 2000). No entanto, somente quando se enxerga essa via de contato com clareza é que se pode perceber a importância da modificação do discurso feito durante o aconselhamento, incluindo a temática da sorodiscordância no pré e no pós-teste, de modo a proporcionar maior subsídio a pacientes que provavelmente nunca mais serão vistos nesse serviço, mas que serão afetados decisivamente pelas primeiras orientações que the forem dadas.

Encontramos, nesse sentido, resultados próximos aos dados de Silva (2007), que entrevistou seis médicos com experiência em ambulatórios públicos e que prestavam assistência às pessoas com HIV/AIDS no município do Rio de Janeiro. O objetivo de seu estudo foi identificar que estratégias ou intervenções são utilizadas pelos médicos para reforçar a utilização do preservativo, especialmente em casais sorodiscordantes. Ao final do estudo, Silva mostrou a preponderância do modelo biomédico em relação às questões relativas à sorodiscordância e, como consequência, a não observância das subjetividades que influenciam o processo saúde-doença. Avaliou as estratégias utilizadas pelos médicos como negativas, porque apagam a condição do casal descontextualizando-o de suas histórias de vida.

Em relação às dificuldades encontradas para trabalhar com "o público sorodiscordante", destaca-se nas entrevistas justamente a questão do não uso do preservativo, mais precisamente a resistência do soronegativo em utilizá-lo rotineiramente a fim de garantir a continuidade de sua condição, conforme pode ser percebido na entrevista abaixo: Entrevistadora: "Que dificuldades você encontra para trabalhar com esse público?" 
Entrevistado: "Principalmente no uso da camisinha, não é nem o doente. O que tem a SIDA, né? Tomar medicamento, nada disso. É o parceiro" (Técnico 8).

O uso de preservativos entre casais sorodiscordantes é percebido como inconsistente pelos profissionais de saúde. Apenas uma profissional de saúde "acredita" que os seus pacientes usam preservativos em "todas" as relações. Todos os outros entrevistados foram unânimes em afirmar que a utilização dos preservativos é falha. A entrevista abaixo é um exemplo de discurso recorrente sobre a questão:

Entrevistadora: Você acha que os casais sorodiscordantes usam preservativo em todas as suas relações? Como vê esta questão? Entrevistado: Não. Um grande problema. Acho que não, acho que é muito difícil o próprio paciente assumir para o profissional de saúde que ele não usa. Ao mesmo tempo, é muito dificil ficar na relação anos a fio é... é... sem usar o preservativo, ainda mais com uma das partes... Se uma das partes não sabe... Se ambas as partes sabem, muitas vezes a outra parte acha, porque já convive há anos e nunca foi contaminado... que o tempo vai dizendo por ele mesmo, como se isso fosse acontecer assim, por ele mesmo. Por exemplo, o parceiro acha: não, o meu parceiro está indetectável... ah, então eu acho que ele não me contamina. Então isso vai entrando em uma contabilidade, em um jogo de perdas que é quase com se tiver que ter, vai ter, vai ser um destino, sabe, porque tudo já foi feito, entendeu? Não aguenta mais. (Técnico 2)

Surpreende que nenhum "técnico" tenha falado sobre práticas sexuais, principalmente, às pessoas que oferecem baixo potencial de infecção. A sexualidade dos casais sorodiscordantes ainda representa tabu e por isso ainda não há compreensão sobre ela.

Outro ponto polêmico recai sobre os desejos reprodutivos. Em 2002, Paiva, Lima, Santos, Ventura-Filipe e Segurado indicavam pouco acolhimento dos serviços de saúde em relação a esse tema, mesmo nos chamados centros de excelência. Oliveira e França (2003) mostraram que as demandas reprodutivas, em geral, são tomadas como problema a ser enfrentado pelos profissionais de saúde com a finalidade do controle de transmissão vertical. Estudo recente realizado por Rossi (2010) verificou que os profissionais de saúde de todo o país têm real dificuldade de identificar as demandas reprodutivas relacionadas ao público soropositivo.

Aspectos sobre procedimentos relativos à reprodução, estratégias sobre redução de riscos e encaminhamentos adequados para a rede de serviços são totalmente desconhecidos pelos profissionais de saúde, mesmo com a publicação do "Consenso" que destinou parte específica sobre o tema em sua última edição. Na pesquisa em questão encontramos variadas percepções sobre este tema; no entanto, de forma geral, muitas dúvidas estão presentes no cotidiano dos serviços, revelando desconhecimento e despreparo dos profissionais para identificar e acompanhar as demandas reprodutivas (obviamente, com exceções), como pode ser visto nos trechos das entrevistas que seguem abaixo:

Entrevistadora: "Quais as principais demandas desse público especifico?"

Entrevistado: . . . Não sei... psicológicas? Eu não sei agora você me pegou. De um apoio psicológico? Porque a gente entra aqui e já começa a pegar uma briga familiar, né... a consulta não rende, porque envolve outras coisas. Então, eu acho que a principal, a procura principal talvez seja de um apoio que não existe, um trabalho, talvez um grupo no Pela Vida, na ABIA, que tivesse voltado para isso. Não sei, todo mundo está muito despreparado para este trabalho. (Técnico 11)

Entrevistado: Não, específica? Não. Especifica? Não. Tem a demanda de todos os outros pacientes e tem a demanda desses que eu não consigo lembrar assim, é... Não vejo eles com nenhum sentimento assim, de proteção, nem de... Um deles eu sei que já fez acompanhamento com o pessoal da saúde mental, que ficou um tempo, mas, só que eu saiba e também nem sei se foi por essa questão; mas não vejo nenhuma demanda específica não. Fogem muito do assunto, a gente sempre bate na mesma tecla. Pra mim, como eu vejo o paciente muito tempo assim, 
então eu falo sempre da questão do preservativo, a questão e tal. Como falo para os outros também, né... Pra mim, assim, não é muito clara essa diferença não. (Técnico 7) Entrevistado: Eu acho até... que seria importante a gente ter um acompanhamento mais assim, especifico... com esta questão da sorodiscordância...

Entrevistadora: Mas por quê?

Entrevistado: De informar... de acompanhar... a gente fica preocupado... se de repente a gente tá... até que ponto também a gente pode estar indo. Essa demanda que você esta falando, é que eu não estou entendendo assim... O que eles querem... O que eles precisam... O quê? ... (Técnico 3)

$\mathrm{O}$ tema da reprodução gerou dois tipos mais gerais de discursos na análise dos dados. Se por um lado ela é vista com temor e desconfiança por parte de alguns profissionais, outros estão se abrindo, aos poucos, para discutir sobre o tema. Alguns profissionais ainda têm alguma resistência em relação à possibilidade de reprodução entre casais sorodiscordantes. Mesmo assim relataram acompanhar "os casos", orientando os pacientes em relação aos procedimentos a serem tomados pelo casal com desejo de ter filhos. Alguns profissionais do serviço em questão dizem aceitar o fato de que um casal com sorologias distintas desejar engravidar; embora assinalem que não foi sempre assim. Já há, portanto, pequenas mudanças no discurso dos profissionais acerca da reprodução, o que é fruto da própria circulação de informações que há nos serviços. Apesar disso, não há um conhecimento pleno das rotinas a serem seguidas para a efetivação desse direito, por exemplo, conforme orientado pelas recomendações oficiais mencionadas anteriormente. Foi possível perceber que as informações sobre a gestação em sorodiscordantes estão mais concentradas nos médicos quando comparados aos outros profissionais de saúde. Ainda assim, eles também têm pouca informação sobre as recomendações que orientam essa conduta. Os entrevistados demonstraram falta de clareza quanto à orientação e à administração de como proceder, na prática, quando um casal deseja engravidar. A entrevista a seguir ilustra bem esse fato:
Entrevistadora: Quando um casal que é sorodiscordante relata que deseja engravidar, comovocêvêestasituação? Hádiretrizes para a orientação? Se sim, definidas por quem? Como você orienta esse casal? Essas diretrizes são de onde? Internas ao trabalho? Entrevistado: . . . Não, isso tem em algum estudo aí, que agora sinceramente eu não me lembro. Mas isso existe. (Técnico 8)

Os profissionais, de forma geral, por desconhecerem a rotina preconizada pelo MS (2010) para casais sorodiscordantes que desejam engravidar, encaminham os pacientes para os serviços que julgam mais qualificados para um possível acompanhamento, mesmo sem ter certeza sobre a rede de referência a ser seguida. Nota-se claramente que essa rede de amparo à gestante soropositiva ou ao homem soropositivo que deseja ser pai ainda está em construção e aos "técnicos" faltam informações e mesmo conhecimentos técnicos que são fundamentais para o seu dia a dia. Este é um assunto que ainda merece maior atenção por parte dos gestores dos serviços, assim como realização de futuras pesquisas. Vejamos abaixo outro exemplo de desconhecimento das recomendações, aliado ao forte estigma que ainda incide sobre a soropositividade e que, ao lado da reprodução, assume contornos mais dramáticos:

Entrevistadora: Quando um casal que é sorodiscordante relata que deseja engravidar, como você vê esta situação? Há diretrizes para a orientação? Se sim, definidas por quem? Como você orienta este casal?

Entrevistado: De duas formas: uma pessoal e outra profissional. A pessoal, eu fico radicalmente irado, revoltado, né?, porque se você queria ter um filho, para que você se prostituiu digamos assim, no bom sentido da palavra, para que você transou com várias pessoas até ficar positivo? Por que você não se preservou para ter um bebê saudável, com qualidade e tudo o mais né?...

Entrevistadora: Pelo que eu pude entender esse é o seu lado pessoal, né? E o seu lado profissional?

Entrevistado: $O$ meu lado profissional diz o seguinte: que todo mundo tem o seu direito e todo mundo tem que ser respeitado, que ai 
o que eu faço? Eu anulo a minha opinião, oriento adequadamente a paciente, e ai sento e converso para aquela gravidez ter segurança é necessário que ela tenha uma carga viral... (Técnico 9).

Nenhum "técnico" fez alusão à questão da gravidez como demanda entre os casais com sorologias diferentes atendidos pelo serviço. Ficou de fora também qualquer aspecto relacionado à rotina pós-exposição sexual em caso de acidente sorodiscordante. Curiosamente, nem os desejos reprodutivos, nem acidentes sexuais foram relatados como ocorrentes no serviço, mostrando, mais uma vez, a 'invisibilidade' desse público e suas demandas. A ausência de planos de ação e estratégias para reconhecer e lidar com tais demandas pode ser justificada pela falta de observação do fenômeno. Afinal, só se pode intervir no que se conhece.

Segundo os profissionais, não houve relatos de usuários sobre acidente sexual (rompimento ou não utilização do preservativo), nem procura explícita, por parte de usuários, para a profilaxia pós-exposição sexual. Esse direito era, portanto, quase desconhecido no serviço em questão. No entanto, é preciso ressaltar que, até o momento de realização da pesquisa, o MS estava realizando, nos estados brasileiros, uma série de oficinas para capacitar profissionais de saúde quanto às novas recomendações presentes no "Consenso" (Saber Viver Comunicação, 2010).

\section{Sobre Atualizações e Capacitações sobre a Temática no Serviço de Saúde}

Todos os "técnicos" entrevistados desconheciam o documento Estratégias Posithivas (MS, 2007) e a maioria conhecia apenas parcialmente as recomendações presentes no "Consenso" de 2010 (seis dos onze entrevistados declararam algum - por vezes vago e parcial - conhecimento). Os entrevistados são unânimes em ressaltar a pouca penetração dessas questões no cotidiano dos serviços:

Entrevistadora: "Você conhece as novas recomendações do 'Consenso', elaborado pelo Ministério da Saúde e publicado agora em outubro de 2010?"

Entrevistado: "Li isso também; eu li. Já tinha assistido no congresso, apesar de que se fala muito pouco em relação a isso, né; A gente não vê isso no serviço público; eu não conheço, eu não conheço" (Técnico 4). Entrevistado: "De outubro, não. De outubro saiu novo 'Consenso?' Eu não sabia ainda; a gente não foi informado. A gente recebeu um adendo de 2007-2008; 2010 não" (Técnico 5).

Segundo o MS, os estados e municípios devem informar e capacitar os serviços para as novas recomendações existentes no "Consenso". No entanto, na prática, isso ainda não havia acontecido, conforme é possível perceber nas falas dos entrevistados.

Sobre as alterações indicadas no documento (PEP e reprodução), quatro entrevistados declararam conhecê-las (sendo todos eles médicos). Esse conhecimento, no entanto, restringia-se à orientação quanto à medicação a ser utilizada, especialmente no caso de uma gravidez, fosse ela programada ou não. O restante da equipe declara desconhecer ou conhecer parcialmente as recomendações ("Conheço dentro do que eu preciso para minha prática", como disse, por exemplo, um entrevistado (Técnico 8), ou "Talvez possa até ter, mas não me despertou a atenção", segundo outro entrevistado (Técnico 1).

Todos os "técnicos" supõem que haverá alterações da rotina já existente nos ambulatórios a partir das novas orientações presentes no "Consenso", embora nem todos saibam dizer com certeza que tipo de mudanças está por vir.

Entrevistadora: "Você acha que o seu fazer profissional ou a rotina do ambulatório pode ser alterada por estas recomendações?"

Entrevistado: Vai, com certeza. Eu acho que você vai proteger o outro, né... Que é o que, na verdade, quem mais pode pegar HIV? O parceiro do paciente, a única coisa que sei que é obrigatório, é a vacina de hepatite. A gente não convoca, faz a vacina, trata, encaminha para o tratamento do figado, mas não pensa no outro, o parceiro dele, se ele tomou vacina? Não sei, talvez seja uma falha minha, de eu não ter pensado tanto no parceiro. (Técnico 1)

Entrevistado: . . . tem a questão da reprodução assistida, mas... não dá para a gente preparar muito, porque eu não tenho nem... 
Eu falei basicamente o que eu ouvi na palestra, o que eu assisti no congresso, mas é muito pouco abordado, hoje ainda. Eu acho muito pouco abordado, hoje ainda. Eu acho muito pouco abordado. Eu, pelo menos aqui em Niterói, eu não conheço nenhum lugar para que eu possa referenciar... Aqui, realmente... porque é trabalhoso, né? Tem que preparar (Técnico 4 ).

Entrevistadora: Já tem rotina para isso?

Entrevistado: Ah, tem que criar rotina, não tem rotina para isso porque não é nem abordado isso com o paciente. (Técnico 4)

Um aspecto muito importante que a entrevista acima assinala é que a partir das modificações propostas pelo "Consenso", há ainda a necessidade de se preparar, adequadamente, os diversos "técnicos" envolvidos na questão, bem como garantir um suporte tecnológico para essa rede de serviços, ou seja, estabelecer fluxos da rotina a serem implementados, garantir a provisão de material e de espaços equipados. O lugar a ser referenciado deve ser claro, as relações entre os diversos serviços precisam estar azeitadas. Caso contrário, o próprio "técnico" se abstém de dar informações, justamente porque elas não se sustentam na realidade da rede de serviços.

Os congressos, as palestras e os seminários fazem parte de uma política de educação permanente. Contudo, uma política efetiva não deve se restringir a situações pontuais. $\mathrm{O}$ aprendizado do profissional nesses cursos precisa ser reelaborado a partir de sua prática no dia a dia dos serviços. Na investigação em questão esta lacuna foi observada.

Todos os entrevistados foram unânimes em dizer que nunca foram atualizados pelo serviço de saúde em relação à temática da sorodiscordância e julgam que tais atualizações seriam úteis ao seu trabalho. Apenas um profissional de saúde declarou não ter interesse em participar de uma capacitação na temática da sorodiscordância e justifica seu desinteresse por não ter nenhum caso de sorodiscordância entre os pacientes que assiste, fato que em si pode estar atrelado à discussão sobre a invisibilidade dessa situação, já apontada anteriormente. Os demais entrevistados consideram que a temática é importante de ser estudada e, entre as razões destacadas, citam a tendência quanto ao aumento da sorodiscordância, a possibilidade de enriquecimento de sua atuação profissional a partir da percepção de diversos especialistas e à possibilidade da troca de experiências com outros profissionais.

\section{Considerações Finais}

Para este artigo importa ressaltar que mesmo que o fenômeno da sorodiscordância seja um fato relativamente novo dentro dos serviços que cuidam de pacientes com HIV/AIDS, ele já demonstra sua concretude, mas, aspectos relacionados à desinformação, ao estigma e à ausência de rotinas claras contribuem para obscurecer a sua magnitude.

A necessidade de mais atenção à sorodiscordância nos ambientes de serviço se deve ao fato de que é um fenômeno que só tende a crescer e que já solicita dos serviços demandas específicas, exigindo também a formatação de rotinas correspondentes.

A sociedade civil organizada, através de ONGs e outros atores, teve um papel muito importante ao pressionar o Ministério da Saúde reivindicando novas práticas de cuidado para os que convivem com o vírus do HIV/AIDS. Em relação à assistência aos casais sorodiscordantes, muito há por ser feito. Os dados demonstram conhecimentos escassos entre os profissionais entrevistados. A invisibilidade desse público determina a inexistência de uma ação mais efetiva dentro da rede de serviço. Há valores que envolvem a questão, que evidenciam o preconceito e o estigma mesmo dentro dos ambulatórios ou centros de referência.

A educação permanente pode contribuir para a superação desses problemas, mas precisa se tornar mais efetiva. A realização de reuniões rotineiras de serviço, de grupo e de estudo envolvendo as diversas especialidades poderia contribuir.

O conhecimento das estratégias definidas pelo MS como as estratégias de prevenção posithiva e as recomendações para reprodução em casais sorodiscordantes/soroconcordantes que desejam engravidar também deve ser uma preocupação de gestores e, por conseguinte, dos profissionais de saúde, pois é a partir daí que o serviço assistencial poderá elaborar sua pró- 
pria rotina interna de cuidado em relação aos pacientes sorodiscordantes, ajudando também a construir com as demais instâncias (Estados e Municípios) uma rotina clara de referenciação nos casos em que a situação assim o exigir. A publicização dessa rede de referência também é um fator imprescindível para o êxito do trabalho.

Conforme já mencionado, a questão da sorodiscordância é relativamente nova no cenário dos ambulatórios brasileiros. Além das questões assinaladas, a cultura institucional também é um fator interferente nessa situação: os processos de alteração de rotina, se permitidos ou estimulados, são demorados e demandam a compreensão de todos os envolvidos, exigindo muito cuidado em sua implantação. As rotinas não estão bem discutidas no nível dos serviços, o que provoca o estabelecimento de condutas equivocadas, e, muitas vezes, de acordo com a valoração pessoal do "técnico" que está atendendo no momento. Além disso, a literatura disponível é escassa e recente, o que dificulta o acesso de muitos profissionais de saúde envolvidos com a questão.

Situações como falta de profissionais especializados, baixos salários - que via de regra provocam a evasão de tais profissionais da rede pública -, carga horária reduzida, acúmulo de empregos, falta de atualização e reciclagem e chefias arbitrárias são também fatores externos que dificultam, ou até mesmo impossibilitam, a visão de um projeto único para a saúde.

Já há consenso sobre a necessidade de se fortalecer o conceito de integralidade na tentativa de ver o ser humano como um todo, buscando uma aliança entre diversos saberes que se colocam no campo profissional e evitando, assim, a parcialização do indivíduo e, muitas vezes, a pouca efetividade dos tratamentos preconizados. Por isso, a questão da sorodiscordância se coloca como um desafio: ela representa a possibilidade de ampliar olhar dos profissionais para além do indivíduo isolado, percebendo-o, portanto, inserido em suas relações sociais (no caso, afetivo- sexuais).

É necessário ressaltar que não se trata aqui de culpabilizar os profissionais de saúde por uma organização da saúde que os transcende, mas de evidenciar essa lógica partida, cindida, que penetra o ambiente dos serviços e impede a vi- sualização da prevenção integrada à assistência (Lago, 2011).

A integralidade das ações em todas as suas dimensões deve ser um alvo a ser perseguido por todos os profissionais (de gestão ou dos serviços) comprometidos com a qualidade das ações em saúde.

\section{Referências}

Barcellos, N. (2009). Prevenção Posithiva: Aspectos clínicos. In J. C. Raxach, I. Maksud, C. Pimenta, \& V. Terto Jr. (Orgs.), Prevenção Posithiva: Estado da arte. Coleção ABIA: Vol. 8. Políticas Públicas (pp. 13-22). Rio de Janeiro, RJ: Associação Brasileira Interdisciplinar de AIDS.

Conselho Nacional de Saúde. (2007, jan.). Resolução 196/96 sobre Pesquisa Envolvendo Seres Humanos. Brasília, DF: Autor.

Fontenelle, D., \& Machado, A. (2002). Atendimento interdisciplinar a parceiros sorodiscordantes. In I. Maksud, V. Terto Jr., M. C. Pimenta, \& R. Parker (Orgs.), Conjugalidade e AIDS: A questão da sorodiscordância e os serviços de saúde (pp. 89-92). Rio de Janeiro, RJ: Associação Brasileira Interdisciplinar de AIDS.

Hallal, R., Ravasi, G., Kuchenbecker, R., Greco, D., \& Simão, M. (2010). O acesso universal ao tratamento antiretroviral no Brasil. Revista Tempus Actas em Saúde Coletiva, 4(2), 53-65.

Herzlich, C. A. (2005). Problemática da Representação Social e sua utilidade no campo da doença. Physis: Revista de Saúde Coletiva, 15(Supl.). 57-70.

Knauth, D. (2002). Comentários. In I. Maksud, V. Terto Jr., M. C. Pimenta, \& R. Parker (Orgs.), Conjugalidade e AIDS: A questão da sorodiscordância e os serviços de saúde. Rio de Janeiro, RJ: Associação Brasileira Interdisciplinar de AIDS.

Lago, E. L. M. (2011). Sorodiscordância e equipe profissional: Estudo qualitativo da assistência em ambulatório de HIV/AIDS no Município de Niterói (Dissertação de mestrado, Pontifícia Universidade Católica do Rio de Janeiro, RJ, Brasil).

Maksud, I. (2007). Casais sorodiscordantes: Conjugalidade, práticas sexuais e HIV/AIDS (Tese de doutorado, Instituto de Medicina Social, Universidade do Estado do Rio de Janeiro, RJ, Brasil). 
Maksud, I. (2012, June). Silêncios e segredos: Aspectos (não falados) da conjugalidade face à sorodiscordância para o HIV/AIDS. Cadernos de Saúde Pública, 28(6), 1196-1204. Recuperado em http://www.scielo.br/scielo.php?pid=S0102$-311 X 2012000600018 \&$ script $=$ sci_arttext

Maksud, I., Terto, V., Jr., Pimenta, M. C., \& Parker, R. (Orgs.). (2002). Conjugalidade e AIDS: A questão da sorodiscordância e os serviços de saúde. Rio de Janeiro, RJ: Associação Brasileira Interdisciplinar de AIDS.

Mattos, R. A. (2004, set./out.). A integralidade na prática (ou sobre a prática da integralidade). Cadernos de Saúde Pública, 20(5), 1411-1416. Recuperado em http://www.scielo.br/pdf/csp/ v20n5/37.pdf

Mattos, R. A. (2009). Repensando a organização da Rede de Serviços de Saúde a partir do princípio da integralidade. In R. Pinheiro \& R. A. Mattos (Orgs.), Razões públicas para a integralidade em saúde: O cuidado como valor (pp. 369-383). Rio de Janeiro: Associação Brasileira de Saúde Coletiva.

Ministério da Saúde. (2000). Aconselhamento em DST/HIV/AIDS: Diretrizes e procedimentos básicos (4. ed.). Brasília, DF: Autor.

Ministério da Saúde. (2007). Estratégias Posithivas. Brasília, DF: Autor.

Ministério da Saúde. (2010, out.). Recomendações para a terapia antirretroviral em adultos infectados pelo HIV - Suplemento III: Tratamento e prevenção. Brasília, DF: Autor.

Oliveira, L. A., \& França, I., Jr. (2003). Demandas reprodutivas e a assistência às pessoas vivendo com HIV/AIDS: Limites e possibilidades no contexto dos serviços de saúde especializados. Cadernos de Saúde Pública, 19(Supl. 2). Recuperado em http://www.scielo.br/scielo.php?pid=S0102-311 X2003000800013\&script=sci_arttext

Paiva, V., Lima, T. N., Santos, N., Ventura-Filipe, E., \& Segurado, A. (2002). Sem direito de amar?: A vontade de ter filhos entre homens (e mulheres) vivendo com o HIV. Psicologia USP, 13(2), 105-133. Recuperado em http://www.scielo.br/scielo.php?pid=S0103$65642002000200007 \&$ script $=$ sci_arttext

Parker, R., \& Camargo, K. R., Jr. (2000). Pobreza e HIV/AIDS: Aspectos antropológicos e sociológicos. Cadernos de Saúde Pública, 16(Supl. 1), 89-102. Recuperado em http://www.scielosp. org/scielo.php?script=sci_arttext\&pid=S0102$-311 \mathrm{X} 2000000700008$
Polejack, L. (2001). Convivendo com a diferença. dinâmica relacional de casais sorodiscordantes para o HIV/AIDS (Dissertação de mestrado, Departamento de Psicologia, Universidade de Brasília, DF, Brasil).

Raxach, J. C., Maksud, I., Pimenta, C., \& Terto, V., Jr. (Orgs.). (2009). Prevenção Posithiva: Estado da arte. Coleção ABIA: Vol. 8. Políticas Públicas. Rio de Janeiro, RJ: Associação Brasileira Interdisciplinar de AIDS.

Remien, R. R. (2002). Uma revisão dos desafios para casais sorodiscordantes e questões de saúde pública: Implicações para intervenções. In I. Maksud, V. Terto Jr., M. C. Pimenta, \& R. Parker (Orgs.), Conjugalidade e AIDS: A questão da sorodiscordância e os serviços de saúde (pp. 2125). Rio de Janeiro, RJ: Associação Brasileira Interdisciplinar de AIDS.

Remien, R. H., Carballo-Dieguez, A., \& Wagner, G. (1995). Intimacy and sexual risk behavior in serodiscordant male couples. AIDS Care, 7(4), 429-438.

Rossi, A. S. (2010). Demanda e barreiras para o acesso a serviços de reprodução assistida para pessoas vivendo com HIV no Brasil: Perspectivas de gestores, profissionais e usuários (Tese de doutorado, Universidade de Campinas, SP, Brasil).

Saber Viver Comunicação. (2010, dez.). Gravidez planejada nas unidades de saúde. Profissionais de saúde receberão treinamento para garantir o direito de casais afetados pelo HIV de ter filhos. Saber Viver Profissional de Saúde, 21. Recuperado em http://saberviver.org.br/publicacoes/ gravidez-planejada-nas-unidades-de-saude/

Silva, A. M. (2007). Entre a cama e o ambulatório: A biomedicina e a vida sexual dos casais sorodiscordantes com HIV/AIDS (Dissertação de mestrado, Universidade do Estado do Rio de Janeiro, RJ, Brasil).

Spink, M. J. (2004). O estudo empírico das representações sociais. In M. J. Spink (Org.), O conhecimento no cotidiano: As representações sociais na perspectiva da Psicologia Social (pp. 85108). São Paulo, SP: Brasiliense. 